\title{
Solar-Powered Improved Full Bridge Resonant Inverter for High-Frequency Industrial Applications
}

\author{
Upasana Sapra $^{\mathrm{a}, 1}$, Aiswarya Sakthivel ${ }^{\mathrm{b}}$, X.Shobana Macdalin ${ }^{\mathrm{b}}$, S.Siva Ranjini ${ }^{\mathrm{b}}$ \\ ${ }^{a}$ Assistant Professor, SRM TRP Engineering College, Trichy, TN, India \\ ${ }^{\mathrm{b}}$ UG Student, SRM TRP Engineering College, Trichy, TN, India
}

\begin{abstract}
Electrical energy consumption is alarmingly rising, but the availability of conventional sources is limited. To meet the increasing demand; the implementation of non-conventional sources is the need of the hour. Solar energy is the most sustainable alternative for power generation among non-conventional sources families. Resonant inverters are used in low-power high-frequency induction heating appliances. Full-bridge resonant inverters are most commonly used to convert solar received power into the suitable form required for highfrequency application device by providing maximum power to the load at resonant frequency The aim of the paper is to analyze the working of the resonant inverter by taking the input supply from the solar panel and converting the obtained dc input to ac input through the resonant inverter. This obtained output is supplied for the high-frequency industrial application which mainly includes Induction frequency heating Applications. Induction heating is one of the techniques used in casting foundry for the treatment of metals. It involves the heat treatment of the metals namely annealing, hardening tempering method. goes here.
\end{abstract}

Keywords. Solar Energy, Induction heating, resonant inverters

\section{Introduction}

Solar energy is a renewable energy resource where it takes the energy from the sun and is one of the powerful energy resources and also it is a truly renewable energy resource because it is available in all the areas of the world and it is available entirely for at most several billion years as according to the scientist's research and also we cannot run out of the solar energy. Solar energy also has many advantages where it is available for nearly half of the day and also during night time the energy can be stored and used accordingly, also it has an advantage of minimum maintenance costs apart from the initial costs for the setup of the solar plant. It also has the advantage of the usage of solar energy for diverse applications.

This paper is developed to improve the efficiency as well as to reduce the losses that is produced in the switching off and on of the semiconductor switching devices which in turn reduces the power losses in the circuit [1-2].

\footnotetext{
${ }^{1}$ Upasana Sapra, Assistant Professor, SRM TRP Engineering College, Trichy, TN, India; Email:
} upasana.s@trp.srmtrichy.edu.in. 
Use of the conventional Pulse Width Modulation techniques in the inverters provides distorted current and voltage but the cost of higher switching losses occurs due to high switching frequencies. The efficiency of the inverter depends mainly on the power losses which is a sum of the conduction losses and switching losses where in the switching losses are mainly dependent on Supply voltage, Load current, Operating frequency, Rising and falling time of the switch voltage and current [2-3].

The switching losses mainly depend on the transistor current and voltage during the turn on and off of the process. The switching losses occur due to hard switching conditions which mean they are switched at either when the current or voltage is high. The switching losses were tested in a normal inverter has been calculated in the range of $500 \mathrm{~W}$ in a normal VSI inverter [4].

The resonant inverter is mainly used for several applications as compared to the normal inverter because of the soft-switching characteristics and it has the advantage of reduced switching losses, small size, and less weight of the passive components [5], which are obtained by the ZVS and ZCS. The resonant inverter mainly consists the semiconductor switching devices namely MOSFET, IGBT, etc., and includes the resonant tank circuit which includes the LC components connected either in series or parallel connection depending on the type of the application. The frequency at which the resonance condition occurs for the resonant tank circuit will be taken as the switching frequency for the semiconductor switching devices in the resonant inverter. The diagram of the resonant inverter is shown in the Figure 1.

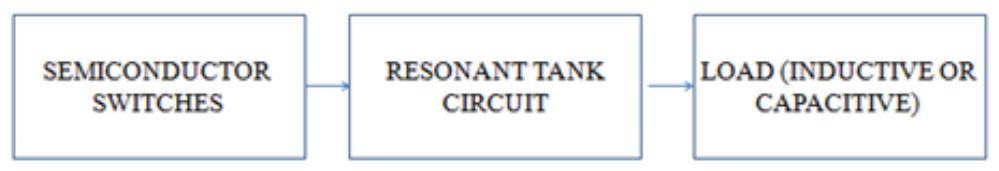

Figure 1. Block diagram of resonant Inverter

There are many types of resonant inverters in which series resonant converter has an advantage of good efficiency but a disadvantage of output voltage regulation in light load conditions, similarly parallel resonant inverter has good output voltage regulation but the efficiency is a bigger drawback. Among the hybrid converters connections namely LCC, LLC and CLL wherein LCC and CLL consists of ripples in the output voltage, when convertors are needed for high voltage applications the output voltage should be free from ripples [5]. The LLC topology is preferred because it is free of ripples and the efficiency obtained is higher compared to LCC and CLL. LLC resonant converter gains attention high value because it has an ability to operate at higher frequencies.

Induction heating is a method used for heating the metals through the electromagnetic induction method where the heat is generated in the metal through the eddy currents. The induction heating application consists of an electromagnet and electronic oscillator [6]. The continually varying magnetic field passes through the object which in turn generates the current inside the metals called the eddy currents [7]. 


\section{Methodology}

The input for resonant inverter is the solar energy which is obtained from the solar panel and it is DC voltage and this DC voltage may contain some harmonics and this DC voltage can be filtered using passive filtering components namely LC filter and using this filtering method the pure DC voltage is obtained without any harmonics. The Block diagram of Solar Powered Improved Full Bridge Resonant inverter is in Figure 2.

This DC voltage is then passed to the resonant inverter consisting of four MOSFET semiconductor switching devices and also a resonant tank circuit consisting of an LC resonant network where the frequency of resonance is taken as the frequency of operation of the semiconducting switching devices. The principle of operation in the resonant inverter is that the frequency of operation of semiconductor switching devices will be the same as that of the resonant frequency of the tank circuit consisting of an LC network.

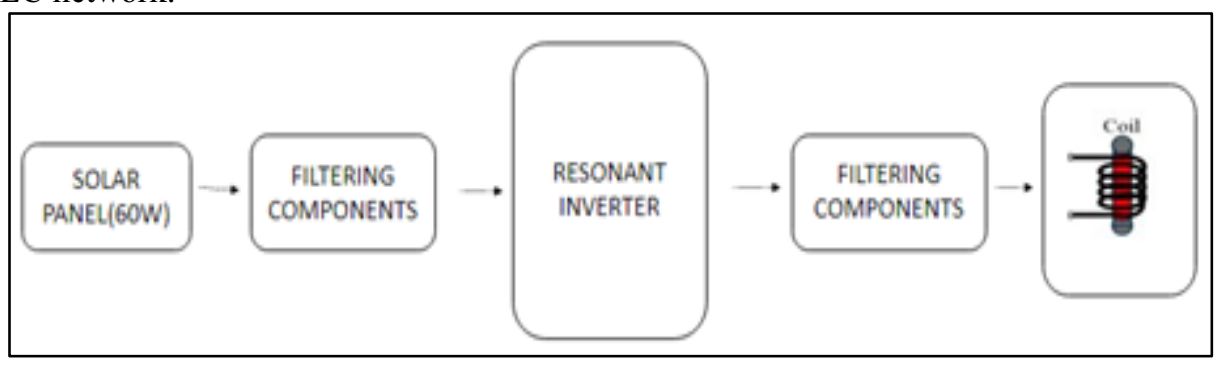

Figure 2. Block Diagram of proposed model

Let the resonant angular frequency be $\omega_{\mathrm{o}}$

$$
\omega_{0}=2 \pi f_{0}
$$

Where $f_{o}$ is the frequency of resonance.

Let the angular frequency of operation of semiconductor switching devices be $\omega$.

$$
\omega=\omega_{\mathrm{n}} / \omega
$$

Where $\omega_{\mathrm{n}}$ - normalized operational frequency

where f-switching frequency.

$$
\omega=2 \pi f
$$

The output from the resonant inverter is $\mathrm{AC}$ which consists of several harmonics and it will not be a pure $\mathrm{AC}$ and this $\mathrm{AC}$ is then purified using passive filtering components mainly LC filter and the pure AC is obtained without any harmonics. The $\mathrm{AC}$ which is to be given load is not of the required voltage and then the output is passed to the high-frequency transformer and the required output that is to be given to the load is obtained and then the voltage is given to the load which would be the Induction Heating application which can be represented as a series combination of inductance and resistance which together is represented as induction coil for the induction heating application. 


\section{Simulation Diagram}

The simulation diagram of the Solar Powered Improved Full Bridge Resonant inverter for High Frequency Industrial application is shown in the Figure 3. The simulation was carried out in MATLAB R2018a version.

The simulation diagram consists of the following parts mainly solar panel then filtering components which are connected to obtain the DC output. The DC voltage is given to the resonant inverter wherein it consists of four semiconducting switching devices and the resonant tank circuit and the load is connected which is mainly the inductive heating application which is represented as a series combination of inductance and resistance.

Table 1. Simulation Results

\begin{tabular}{cll}
\hline S.No. & Component & Value \\
\hline 1. & Solar panel & $60 \mathrm{~W}$ \\
2. & Inductor & $42 \mathrm{micro}$ henry \\
3. & Capacitor & $0.35 \mathrm{micro}$ farad \\
4. & Filter Capacitor & $5.5 \mathrm{micro}$ farad \\
5. & Load resistor & $190 \mathrm{kohm}$ \\
6. & Output Frequency & $200 \mathrm{~Hz}$ \\
7. & Output Voltage & $48 \mathrm{~V}$
\end{tabular}

The simulation diagram results consists of input voltage i.e., the voltage from the dc voltage and the voltage output from the linear transformer and the output voltage and output current from the load and the y axis is taken as time in seconds. Table 1. Shows the ratings of components values used in simulation.

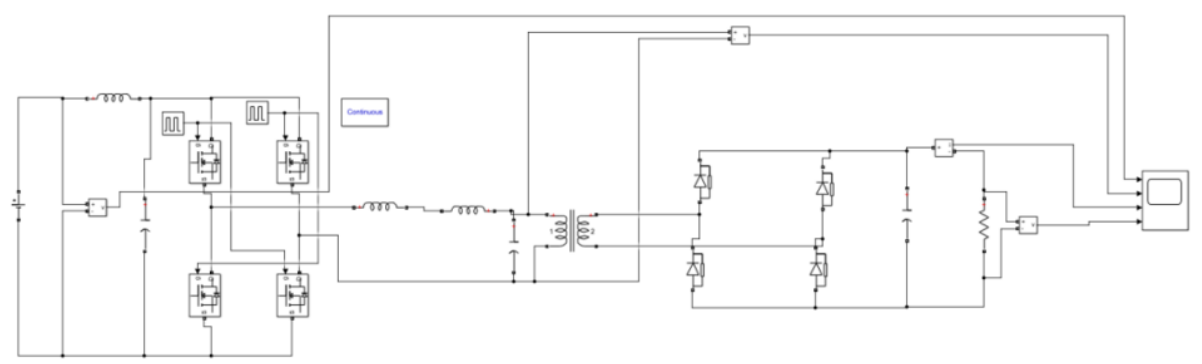

Figure 3. Simulation diagram

The results are obtained and the results of the simulation are shown in the Figure 4. 


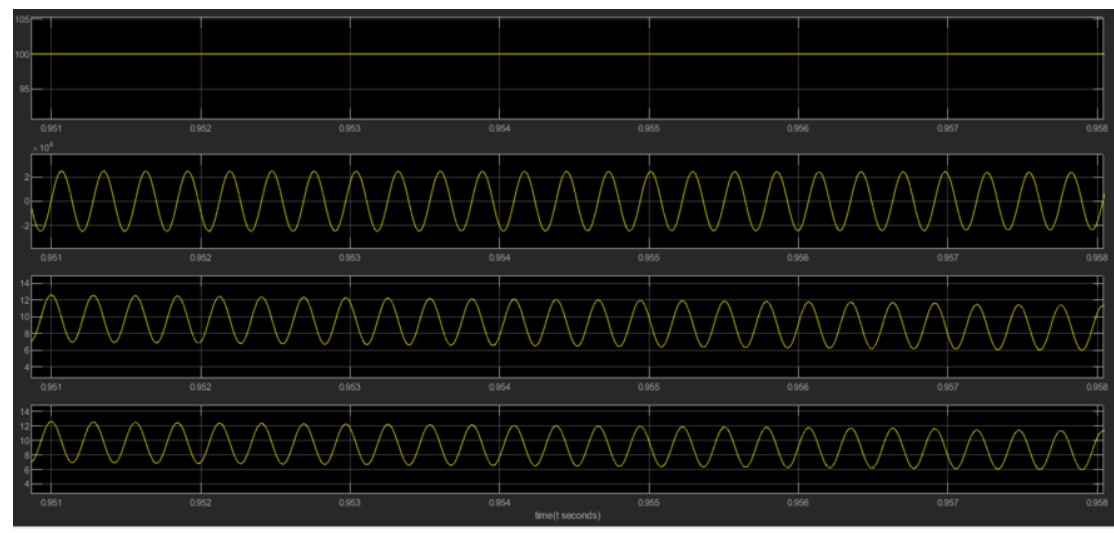

Figure 4. Simulation diagram results

\section{Conclusion}

The simulation output represents the input from the solar panel and the output current and voltage waveform. The results obtained from the simulation diagram in the MATLAB Simulink shows that the switching losses are less as compared to the usage of the normal inverter. At this value of input, the corresponding output has less switching losses due to the resonant phenomenon. The results also confirm that the ac wave obtained as an output and low harmonics content. The switching losses are reduced and the high frequency obtained so can be used for industrial heating purposes.

\section{References}

[1] Sayed, K., Abo-Elyousr, F., Abdelbar, F. N., \& El-zohri, H. (2018). Development of Series Resonant Inverters for Induction Heating Applications. European Journal of Engineering Research and Science, 3(12), 36-39. https://doi.org/10.24018/ejers.2018.3.12.975

[2] Jin, J., Kim, M., Han, J., Kang, K., \& Jung, J.-H. (2020). Input voltage selection method of half-bridge series resonant inverters for all-metal induction heating applications using high turn-numbered coils. Journal of Power Electronics, 20(6), 1629-1637. https://doi.org/10.1007/s43236-020-00147-y

[3] Varecha, P., Makyš, P., Sumega, M., \& Sovička, P. (2019). Power losses analysis in MOSFET 3-phase high current power inverter for automotive application area. Transportation Research Procedia, 40, 571-578. https://doi.org/10.1016/j.trpro.2019.07.082

[4] C, B., \& Rajesh Babu, R. S. (2018). Analysis of High Voltage High Power Resonant Converters. International Journal of Power Electronics and Drive Systems (IJPEDS), 9(1), 174. https://doi.org/10.11591/ijpeds.v9.i1.pp174-179

[5] Mao, S., Popovic, J., Ramabhadran, R., \& Ferreira, J. A. (2015). Comparative study of half-bridge LCC and LLC resonant DC-DC converters for ultra-wide output power range applications. 2015 17th European Conference on Power Electronics and Applications (EPE'15 ECCE-Europe), 1-10. https://doi.org/10.1109/EPE.2015.7311786

[6] Haema, J., \& Phudungthin, R. (2019). Full Bridge Resonant Inverter for Blade Induction Heating Application. Energy Procedia, 156, 391-395. https://doi.org/10.1016/j.egypro.2018.11.106

[7] Khatua, M., Kumar, A., Yousefzadeh, V., Sepahvand, A., Doshi, M., Maksimovic, D., \& Afridi, K. K. (2018). High-Performance Megahertz-Frequency Resonant DC-DC Converter for Automotive LED Driver Applications. 2018 IEEE Energy Conversion Congress and Exposition (ECCE), 2186-2192. https://doi.org/10.1109/ECCE.2018.8558088 